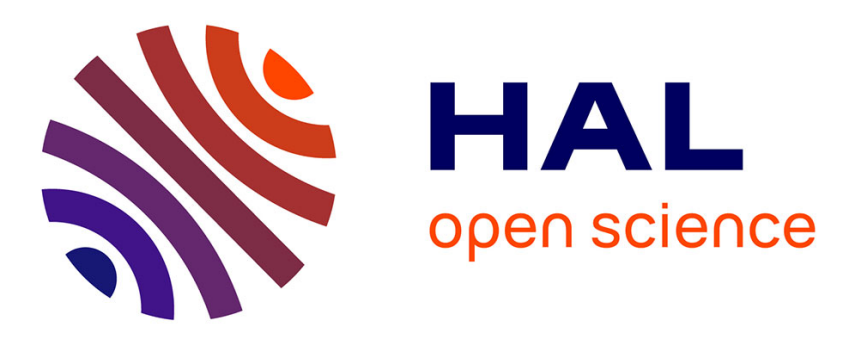

\title{
Using accreditation criteria for collaborative quality enhancement
}

Jens Bennedsen, Siegfried Rouvrais, Robin Clark, Katriina Shrey-Niemenmaa

\section{To cite this version:}

Jens Bennedsen, Siegfried Rouvrais, Robin Clark, Katriina Shrey-Niemenmaa. Using accreditation criteria for collaborative quality enhancement. ICL 2015: International Conference on Interactive Collaborative Learning, Sep 2015, Florence, Italy. 10.1109/ICL.2015.7318049 hal-01359090

\section{HAL Id: hal-01359090 \\ https://hal.science/hal-01359090}

Submitted on 27 May 2021

HAL is a multi-disciplinary open access archive for the deposit and dissemination of scientific research documents, whether they are published or not. The documents may come from teaching and research institutions in France or abroad, or from public or private research centers.
L'archive ouverte pluridisciplinaire HAL, est destinée au dépôt et à la diffusion de documents scientifiques de niveau recherche, publiés ou non, émanant des établissements d'enseignement et de recherche français ou étrangers, des laboratoires publics ou privés. 


\section{Using Accreditation Criteria for Collaborative Quality Enhancement}

\author{
Jens Bennedsen \\ School of Engineering \\ Aarhus University \\ DK-8000 Aarhus, Denmark \\ jbb@ase.au.dk \\ Siegfried Rouvrais \\ Telecom Bretagne \\ Brest, France \\ siegfried.rouvrais@telecom-bretagne.eu
}

\author{
Robin Clark \\ School of Engineering and Applied Science \\ Aston University \\ Birmingham, United Kingdom \\ r.p.clark@aston.ac.uk \\ Katriina Schrey-Niemenmaa \\ Helsinki Metropolia University of Applied Sciences, \\ Helsinki, Finland \\ katriina.schrey@metropolia.fi
}

\begin{abstract}
This paper describes a process to enhance the quality of higher education. At the heart of the process is a crosssparring collaborative model, whereby institutions are critical friends. This is based on a prior self-evaluation, where the institution / programme identifies quality criteria it wants to improve. Part of the process is to ensure the documentation of best practices so that they can be shared with others in a so called market place. Linking the best practices to a criterion makes them searchable on a large scale. Optimal pairings of institutions can then take place for the cross-sparring activities.
\end{abstract}

Keywords- Quality in engineering education, accreditation, quality enhancement, cross-sparring

\section{INTRODUCTION}

Improving the quality of education and training systems is often set as a target for ensuring that a country's economy develops and prospers to become smart, sustainable and inclusive. One example is the so called Modernisation Agenda presented by the European Union [1]. More specifically, with this agenda, a goal has been set to improve the quality and relevance of higher education.

Within this demanding environment, the scrutiny of the quality of institutional offerings has become increasingly important, as has the role of the Quality Assurance Bodies globally [2]. Theses bodies monitor the quality of higher education provision and their codes, frameworks and requirements have become a key consideration in how institutions develop their programmes, and consider the experience of their students [3]. For engineering education, such bodies exist in many forms such as ENAEE (European Network for Accreditation of Engineering Education) with their EUR_ACE® framework [4], ABET (Accreditation Board for Engineering and Technology, USA)[5], Engineers Australia $[5,6]$, the Quality Assurance Agency for Higher Education (UK) [7], the French Commission des Titres d'Ingénieur [8], and the Danish Accreditation Institution [9]. All of these bodies have similarities in their frameworks but some differences in their criteria, the referred indicators, and in the quality assurance perspectives or underlying accreditation process detail.

This paper will explore the role of quality assurance in higher education. Importantly it will focus on what is perhaps the weakest area of quality scrutiny, that whereby quality assurance becomes a driver for quality enhancement. The study will be conducted using the context of a newly established European Union funded ERASMUS+ Project called QAEMP (Quality Assurance and Enhancement Marketplace) and is initially focused on engineering education.

The paper is structured as follows: Following this section, a short overview of accreditation and how it is and has been used is given. Following that, the limitations of accreditations are discussed in Section III. The next section gives a short overview of the criteria used when the institution / programme analyses its strength and weaknesses, and how criteria can be used to enhance the quality of educational programmes and educational institutions. The next section discusses how institutions can share best practice thanks to a market place. Section VI describes the overall process for collaborative quality enhancement. The cross-sparring process described is still under development. Before concluding the paper in section VIII, a future work section describes what is going to happen in the next phase of the QAEMP project.

\section{ACCREDITATION AND ITS PURPOSE}

Many - if not all - of the accreditation systems mentioned in the introduction are seen by institutional stakeholders as something that the institution has to do in order to be allowed to grant diplomas and degrees. It is a process conducted by a special group, typically at a top-management level, and it 
often does not have any real effect on the quality of the education happening at the institution. As [10] notes

The recent UK developments have shown the limitations of an approach that was perceived as too intrusive. A quality assurance system that is perceived as creating work instead of creating quality will not yield the anticipated results. It induces compliance and window dressing. (p. 14)

Throughout history the definition of quality has been expressed in several different ways. At least three different kinds of system can be found [11]. The old universities of Cambridge and Oxford were self-governing institutions where quality was defined by the professors who had the power to remove unsuitable employees and hire new staff by a kind of peer-evaluation process. At the University of Paris, the Chancellor of Notre Dame was the rector and had all the power to make decisions - a quality system decided by topmanagement. Finally in Bologna, the students have the power to 'hire and fire' professors. This is more a quality system driven by customer satisfaction.

Bologna is, however, the odd one out. Quality was not on the general public's agenda before the 1980's [2, 12]. Amaral [11] argues that the reason for the quality need (as seen by government) was based on four factors: massification of higher education, market regulation, new public management and a loss of trust in higher education institutions and their professors.

Quality assessment has two main objectives: quality improvement and accountability. The balance between these two objectives depends on the balance of power between academics and government; (i) if academics have the strongest voice, it focuses more on improvement, (ii) if government has the strongest voice, it focuses more on accountability.

New public management has given rise to the view that the students have become customers. This mindset has naturally given rise to a demand for ensuring customer satisfaction. Consequently in most countries quality assurance and accountability measures have been put in place to ensure that the "academic production system" meets clients' needs and expectations [13].

The accreditation systems today are typically inspired by quality models like EFQM, [14] and the Capability Maturity Model used for software development [15] or SPICE [16] where the focus is on process maturity and continuous improvement rather than a measurement of the current status (even though that consideration is an important part of the quality process).

\section{Boele at al. [17] describe the EFQM model like this:}

The EFQM (European Foundation for Quality Management) model basically looks at an organization, its results, and the way the results lead to learning, improvement and innovation. It was developed for firms but can be applied to any kind of organization.

An accreditation system typically consists of an an assessment model, an assessment process and a measurement framework [18]. The assessment process describes how and when the assessment is done (how data is collected and validated and how the planning is done). The process focuses on the roles and responsibilities of the involved stakeholders, the inputs and the outputs. The assessment process is supported by an assessment model. The assessment model is based on a reference model that defines a set of best practices (or standards) related to the domain that needs to be assessed. It is measurement against these standards that is important as this is then the basis for improving quality. The measurement framework defines the maturity levels to be considered and contains a set of assessment indicators which support the ratings against the various standards.

One of the most established accreditation systems in engineering education is the Accreditation Board for Engineering and Technology (ABET) in the USA. ABET was founded in 1932 and is a federation of 28 engineering and technical societies. Over the years, ABET has been involved in curriculum development as well as accreditation activities. It has expanded not just to cover classical engineering education but also Computer Science. Engineering programmes outside the US have also started to become accredited by ABET. For a historical description of ABET see [19]. ABET describes the rationale for accreditation in the following way [20]:

The ABET accreditation review process is an intensive team effort, and program accreditation is voluntary in the U.S. So why go to the trouble? Because the process yields data and insights, you can use to deliver the best educational experience and preparation for your students.

More than 2,000 professionals from academia, industry, and government carry out every aspect of ABET accreditation. They know their profession's dynamic and emerging workforce needs and review academic programs to ensure they provide the technical and professional skills graduates need to succeed.

ABET accreditation tells your prospective students, peers, and the professions you serve that your program:

- Has received international recognition of its quality.

- Promotes "best practices" in education.

- Directly involves faculty and staff in self-assessment and continuous quality improvement processes.

- Is based on "learning outcomes, " rather than "teaching inputs."

- Can more easily determine the acceptability of transfer credits.

ABET's core business is accreditation and naturally their view on accreditation is indeed a very positive one. Others have a different view on the value and impact of the accreditation process.

\section{LIMITATIONS OF ACCREDITATION}

Evaluation approaches are prevalent within higher education quality processes. These offer institutions the opportunity to explore their programmes through a quality lens and work towards a process of improvement. Unfortunately, in many cases, the focus is very much on quality assurance and 
the latter point, the steps towards improvement, are not fully considered. This tension is captured extensively in the literature $[21,22]$.

Too often quality assurance is seen within institutions as a compliance requirement and the use of the quality assurance process to drive quality enhancement is somewhat tenuous. Quality enhancement takes place within institutions but often the connection with the quality assurance approach is not obvious.

For quality in engineering education, there is a need for a more integrated approach, a model that brings together assurance and enhancement and that can be used across institutions, across disciplines and across countries. With such a model it would afford the community the opportunity to establish international collaborations and to improve international comparability across HEIs. There have been many European projects on quality assurance (e.g. EUA projects) but they rarely consider the problems with accreditation such as the required resources, complexity, delays between the evaluation rounds, poor feedback, poor quality loops and the need for continuous education development.

In order to address this weakness, an EU funded ERASMUS+ project has been initiated.

The project comprises 8 institutions and their mutual interest was in the implementation and development of the CDIO (Conceive Design Implement Operate) Approach to engineering education [23]. The eight European universities are Reykjavik University, Iceland; Turku University of Applied Sciences, Finland; Aarhus University, Denmark; Helsinki Metropolia University of Applied Sciences, Finland; Umeå University, Sweden; Telecom Bretagne (a French Grande Ecole), France; Aston University, United Kingdom; Queens University Belfast, United Kingdom.

In exploring a more proactive approach to quality enhancement, the partners developed a project idea similar to the process employed within the CDIO community, an area of mutual interest. The approach taken will make use of selfevaluation against a set of criteria (in the case of CDIO this would be the CDIO standards [24]). The element being considered for evaluation could be a module, year of study or complete programme, this will be decided by the institution prior to conducting the self-evaluation. The idea itself builds on work previously conducted across several Nordic universities [25]. The background to this ERASMUS+ project is given in [26].

\section{CRITERIA FOR QUALITY ENHANCEMENT}

In order to ensure a thorough coverage of the applicable standards from the participating countries and beyond, the approach to developing the self-evaluation framework considered:

a) institutional standards and processes

b) national standards and processes (e.g. in the UK, Denmark, Finland, France, Sweden, Iceland)

c) documents relating to regional / global accreditation schemes (e.g. ABET, Queste-SI) d) requirements / guidelines relating to particular learning and teaching frameworks (e.g. CDIO).

\section{A. A reference model including 28 criteria}

From these sources, the key self-evaluation criteria were identified. The resulting draft self-evaluation framework was then analyzed and discussed within the project team and refined appropriately. The literature yielded 28 criteria. The discussion process resulted in some changes that eliminated 2 criteria, but added two new criteria. This formed a final selfevaluation framework based around 28 criteria which were grouped into 10 theme areas as identified below:

- Programme Philosophy: 1

- Programme Foundation: 4

- Learning and Teaching: 5

- Assessment and Feedback: 2

- Skills Development: 4

- Employment: 2

- Research: 1

- $\quad$ Student Focus: 4

- $\quad$ Faculty Development: 2

- Evaluation: 3

Having developed the working list of criteria for the selfevaluation, for each criterion a clear final statement and rationale were articulated in order to ensure a clear and consistent understanding by the evaluators. This is essential as the responses to the framework will support the collaborative process. Particular consideration has been paid to the extent of the framework, as a key objective of the project is to ensure that the approach to quality assurance and enhancement has impact but is not overly demanding in terms of time or paperwork. In other words that it is focused on action and value added to staff, students and the programmes being considered.

For each criterion a measurement rubric has been developed. The rubrics are based on the maturity model approach and are more fully discussed in [27]. The framework will be developed further to identify supporting examples and indicators for each criterion.

\section{B. Self evaluation feedback}

So far two project partner institutions have conducted a self-evaluation according to the reference model introduced above. In one instance, the questions were delivered to the development team of the unit two weeks before the "consensus" discussion meeting. In the meeting there were 6 people present. The discussion itself took 6 hours.

The first impressions suggested that getting together to discuss the self-evaluation in a systematic form was helpful as it helped the participants clarify issues and helped the team to find a common vocabulary and shared understanding [28]. A common understanding was found although for some of the questions it was agreed that the definitions were compromised somewhat in trying to maintain an international context to the 
framework. One development issue raised was that each of the questions should be additionally evaluated according to its importance to the unit.

It was additionally felt that subsequent to completing the session it is important to create a clear and concise report where the agreed enhancement elements are recorded with their related needs.

The unit was sufficiently enthused by the process that it is now looking forward to collaboration with a unit from one of the other partner universities in order to consider specific criteria for enhancement.

\section{SHARING INDICATORS AND GOOD PRACTICE}

Normally self assessment reports for accreditation purposes are prepared within one institution and there is no sharing of knowledge and best practice outside of the institution. However, in many projects, professional sectors, forums, institutions and organisations, best practice is a major focus. In hospitals for example, best practices for taking care of certain kinds of patients are discussed and many reports talk about how better quality can be achieved through utilising other organizations' best practices. Key questions remain such as how do we share best practice, how do we document it and last, but not least, how can one find out about the best practice.

In QAEMP, the best practice is linked to an individual criterion. By linking the best practice to a criterion, it is searchable in a database of best practices so that others can easily find the information. The self-evaluation is the starting point as an institution can identify the criteria they want to improve and from that they can search the database for best practices related to those criteria.

The underlying assumption is that the cross-sparring (coming together) of two degree programmes/institutions will enhance the quality of both programmes/institutions on selected criteria. This naturally leads to the question - what to share, who should cross-spar and how can these institutions/degree programmes actually find each other and collaborate? This is where the Market Place comes in - a virtual place where confidential information can be entered and partners for the cross-sparring can be found.

\section{A. The Market Place}

Giving inspiration to others in their quality enhancement process is very important. The Market Place is a place where good advice on improving quality will be made available to other institutions/degree programmes. In the Market Place, best practice on how institutions have done self-evaluations, quality enhancements etc. will be made available.

The goal of the market place is:

a) Clarify the institutional context;

b) Highlight and make available best practice on how institutions and degree-programmes enhance their quality in different areas (using indicators);

c) Make it possible for institutions and/or degree-programmes to show an interest on specific criteria.
The Market Place serves as a forum for networking, sharing experiences, information and best practices. The quality control of the best practices is inspired by modern web-sites like trustpilot.com and tripadvisor.com. In these, the users can rate (on a five star rating scale) how good they found a particular experience. Feeding the market place requires that the institution firstly makes a self-evaluation. As described previously, many parts of the self-evaluation are equivalent to a typical accreditation process and an institution that has been through that process has already done part of the work.

The Market Place serves also as a repository for finding the best possible partners to collaborate with, i.e. to choose the most appropriate pair of collaborators that will have a major impact on each institution, the pairing process needs to be carefully undertaken to ensure a real win-win situation.

\section{B. Pairing institutions}

A Self Evaluation (SE) is conducted according to an assessment model that specifies a list of $\mathrm{M}$ Quality Criteria (QC) (28 QC in QAEMP). A QC is measured on a maturity scale $\left(\mathrm{S}_{\mathrm{QC}}\right)$. As a result of the marketplace (MP), the community will benefit from a set of self-evaluations (SES of size $\mathrm{S}$ ). To meet the main goals of the cross-sparring model, only the specific QC it is required to enhance are the focus (PC, priority criteria). To find a subset of institutional pairs $\left(\mathrm{SE}_{\mathrm{i}}, \mathrm{SE}_{\mathrm{j}}\right)$ in $\mathrm{SES}$, an institution, upon request, is identified by some PC and the sparring partner by, ideally, a higher QC per PC. Broadly speaking, the institutions are paired such that they differ the most on the criteria maturity that they are interested in (where CoI represents the union of their PC). Some criteria can be seen as more important than others, but in a pair both institutions will prefer to have some QC where one institution is better than the other. For pairing, parameters comprise:

- 3 to 5 PC per institution (i.e. priorities for enhancement). A PC is measured on some maturity scale as QC;

- The expertise of the institution in evaluations (IM), which comprises the number of SE, the number of cross-sparrings, the number of external audits supported, e.g. accreditations;

- The size of the institution (Size) in a 4 scale model, which comprises the number of students enrolled (i.e. small, medium, medium-large, large);

- The institution, programme main discipline, or field (PD), mainly $\mathrm{BSc}$ or $\mathrm{MSc}$ engineering degrees during the QAEMP project;

- The nationality of the institution (Nat), e.g. in order to promote international comparability of education.

The algorithm follows such a pattern:

SubSES $=\left\{\right.$ Forall $\mathrm{i}, \mathrm{j}$ in MP and $\mathrm{m}, \mathrm{n}$ in $\mathrm{CoI}_{\mathrm{i}, \mathrm{j}}$, there exist $\left(\mathrm{SE}_{\mathrm{i}}, \mathrm{SE}_{\mathrm{j}}\right)$ such that

$\mathrm{SE}_{\mathrm{i}} \cdot \mathrm{QC}_{\mathrm{m}}>\mathrm{SE}_{\mathrm{j}} \cdot \mathrm{QC}_{\mathrm{m}}$ AND $\left.\mathrm{SE}_{\mathrm{j}} \cdot \mathrm{QC}_{\mathrm{n}}>\mathrm{SE}_{\mathrm{i}} \cdot \mathrm{QC}_{\mathrm{n}}\right\}$ 
where

$\mathrm{CoI}_{\mathrm{i}, \mathrm{j}}=\{\mathrm{PCs}$ institution $i$ have shown interest in $\} \cup\{\mathrm{PCs}$ institution $\mathrm{j}$ have shown interest in

The more the Market Place is supplied with self evaluations (i.e. SES large), the more productive and impactful the subset of pairs will be. If the subset SubSES remains empty once the algorithm has been applied, the criteria distance is relaxed, i.e. each PC can have an associated importance, when necessary. For the general case, in SubSES, a distance is then calculated for each pairing, based on maturity levels $\mathrm{S}_{\mathrm{QC}}$ and the other institutional parameters (Im, Size, PD, Nat). If the subset SubSES remains too large for a simple consultation, the larger distance between PC and QC is mainly to be used for selection, after ordering.

\section{COLLABORATIVE QUALITY ENHANCEMENT}

In order to address the aforementioned limitations of formal HEI quality assurance frameworks and assessment methods prompted by accreditation or national regulation bodies, a key is to design and implement time effective, targeted and continuous collaborative evaluation processes. Such new processes, relying on self-evaluation models more specific to quality enhancement, can flexibly complement in place quality assurance systems, when they exist.

\section{A. Collaborative focus}

In previous projects [29, 30] a closed group of institutions have self-evaluated and been paired. The sharing of good practice has thus been based solely on the two institutions participating in the cross-sparring. On a more collaborative and larger scale approach, in the QAEMP project, the collaborative model is symmetric, whereby one institution scrutinises the other, and vice-versa. For the purpose of simplicity and manageability, these flexible activities are proposed one-onone, hand-in-hand, on a cross-collaborative basis. The QAEMP focus is not so much on evaluation but rather on a sparring partnership as in sport. Sparring partners ease down on the force when punching; they allow their partner to develop their footwork. The model is not about competing but about supporting, sharing and complementing. An overview of the process is given in Figure 1.

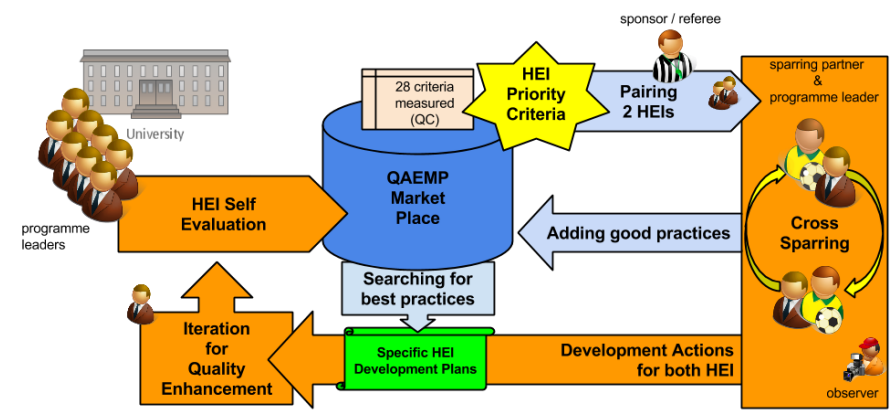

Figure 1 The overall process

\section{B. Time for improvment and development: cross-sparring roles}

As a result of the QAEMP collaborative perspective, a cross-evaluation model has been developed that has the potential to facilitate the dissemination of good practices relating to quality assurance processes and educational best practices among HEIs. The identification of best practices takes place when the actual cross-sparring is conducted.

Cross-sparring is a process that makes feedback more collaborative, concrete and objective, thanks to critical, but discrete brainstorming sessions, where strategies can be discussed, repeatedly contributing to quality assurance with a critical external view.

Institutions can help and learn from each other e.g. in terms of educational programme development or refactoring, as partners for a short period rather than competitors. An external collaborator can identify strengths and challenges free from bias as open questions point out good practices and provide more immediate feedback to programmes for development actions. An effective external collaborator can help an institution to reflect and take stock with greater impartiality than an external formal evaluator where the status and achievement may be more the primary goal.

As in sport, a sparring partner helps to keep a person's eyes on the objectives, learn from experience and stimulate reflectivity. This approach is beneficial both for the institution evaluated, which will get a more objective view on its strengths and potential improvements, and for the sparring partner which may identify best practices that can be useful for their own institution.

Prior to their analysis and site visits both partners are familiar with the self-evaluation documents (including the rubrics, the values for the criteria, the rationale and the indicators). By limiting the number of criteria to be analysed, an external collaborator can produce a short executive report at the end of their site visit, but can also learn themselves from the institution visited. An institution can analyse the feedback carefully and make the necessary corrections or new additions to their enhancement plan.

The 'cross-sparree' has the responsibility to note and reflect upon the good ideas that the 'cross-sparrer' has given when visiting. The 'cross-sparree' will describe the best practice, send the description to the 'cross-sparrer' for validation and commenting and upload that to a web-based market place.

\section{ONGOING AND FUTURE WORK}

The QAEMP project runs during the 2014-2016 period. At the time of writing, some work packages have been completed at their first deliverable phase, namely the self-evaluation model definition and the marketplace software implementation including the pairing algorithm. Some activities are ongoing, namely (i) developing the cross-sparring process, (ii) analysing the SE model using the eight European partner institutions, (iii) generalising the SE model and CS process for other HEIs and disciplines. They are discussed hereafter as ongoing and future work 


\section{A. Developing the cross-sparring process}

\section{1) Characteristics of a cross-sparring process}

In order to meet the expected goals and complement the accreditation system, a cross-sparring process should be flexible (i.e. easy to adapt to changes in context), reactive (i.e. responds in a short period of time to change), targeted (i.e. focused on particular enhancement), simple (i.e. to facilitate use without the need for a lot of time and dedicated resources as for accreditation), compact (e.g. in terms of reporting) and time-efficient. Four main activities have been specified to ensure these properties are realised.

\section{2) Main activities}

A cross-sparring process (CS) has been designed and will be implemented in the second phase of the QAEMP project (Autumn 2015). Once a pair of HEI's has been selected, two instances of the CS process are to take place, with Institution having to visit Institution $_{j}$ and vice-versa. This gives each institution the opportunity to take on the role of both the 'sparrer' and the 'sparree'. Sponsor and observer roles can be added to the process (for process evaluation purposes or 'newbies' wishing to explore the processes). For each pairing, the sparring partner is responsible for preparing, planning and leading the cross-sparring to ensure it conforms with the guidelines and meets the sponsor's requirements. They manage the delivery of the outputs (internal report for the pairing institutions, output for the Market Place, feedback on the process for the sponsor). Sparring requires honesty from both partners and can be mutually beneficial is conducted in the right spirit.

In its actual form, the CS process is composed of four main activities:

- Initialization (e.g. to agree on the selected PC, focus, boundaries, roles and responsibilities and composition of the CS team). This main activity is conducted only once, for the two visits;

- Organization and Preparation (e.g. team preparation, SE consultation, agenda, production and validation of the CS plan, etc.)

- Collection, Analysis, and Discussion (e.g. identify evidence related to the $\mathrm{PC}$, enable identification of best practices, challenges and potential improvement actions at the cross-sparree institution;

- $\quad$ Feedback and Development Plan with actions (memo reporting, Market Place updates, sponsor notification, follow-ups, both sides reporting of good practices).

Based on the analysis, visit and report results, the visited programme team uses the feedback to refine development plans, including actions aimed at enhancing the quality of the programme in all areas. A kit to create a CS report, including templates for partners, a development and action plan is under development. Six artefacts per selected PC are to be addressed: (i) impressive experiences from the visit, (ii) programme strengths, (iii) programme challenges, (iv) the development plan (define the precise actions for improving the quality of education), (v) best practices, and (vi) any open questions.

\section{B. Quality analysis of the self-evaluation model, pairing and cross-sparring process}

The quality of the evaluation model will be analysed from two viewpoints: (i) the quality of the self evaluation questionnaire including the definitions and rubrics, and (ii) the quality and value of the pairing. For these two facets, opinions and data will be collected in two phases from the pilots of the project.

Firstly, after the self-evaluation phase pilots, institutions will be asked to evaluate the content of the self evaluation framework using the following questions:

\section{a) Evaluation for each criterion}

For each criterion feedback on:

- Is the rationale understandable?

- Is the rubric understandable, and in accordance with the general maturity model

- What indicators did you use to argue for the level your programme/institution is on (so that the team can collect a range of indicators for other to look for when doing their self-evaluation)

b) Evaluation of the framework

- Are all criteria relevant?

- Are some of the criteria overlapping?

- $\quad$ Are there missing criteria?

- Is the order of the criteria the best or are there some grouping that would be more logical for you?

Clarity and consistency of understanding will be key features that the evaluation will explore. Teams will also be free to feed back any other items they deem important. Examples may be what kind of discussion did the questions create in the unit, did the process of answering already benefit the continuous development of the unit, differences for instance according to the country, language, discipline and local culture of the university. Additionally, data about the time spent and amount of people involved will be recorded

In the second phase of the project after the cross-sparring, the pilots will be asked to evaluate the pairing for the pilots. This will focus on how beneficial the chosen partner was, how much added value the institution gained from the site visit to the other unit and how successful the visit to one's own unit was.

According to these two evaluations both the self evaluation process and the cross-sparring (including the pairing) will be developed to become more robust and widely usable. Critical aspects are to gain the most added values to the individual units involved - they should be supported to find their own success factors, development issues, good practices to solve problems and priorities in terms of actions. 
Important for the quality of the pairing is the need to define partners who have experiences that can help each other - will it be partners who are very different or partners who have differences in pre-defined parameters? Should the partners be active in the same discipline or perhaps getting ideas from another field? Should they be able to list their own preferences about the cross-sparring partner? These are examples of the questions to be answered as a result of the project evaluation.

\section{Generalization of the model}

Tailoring recommendations to take into account the adaptation of the model to meet specific institutional needs will be explored before completion of the project. As the actual QAEMP partners are mainly in the engineering education category, other disciplines may be considered, as a parameter in the pairing algorithm, e.g. based on the ERASMUS or UNESCO (ISCED) standard classification of disciplines. The Market Place may then not only facilitate comparisons of educational good practices, but also open up to indicators shareable across countries on the basis of uniform criteria, as a complement for example to the EU U-multirank profiles [31] (including teaching \& learning, research, knowledge transfer, international orientation, and regional engagement).

\section{CONCLUSIONS}

The QAEMP project has the potential to more firmly embed the quality enhancement ethos within programmes and institutions as a consequence of engaging with a rigorous accreditation type process. Through sharing and collaboration within and across institutions and countries, the benefits to programmes will go beyond that typically achieved by simply studying case studies and best practice. The dynamic nature of the implemented Market Place and its potential to create an archive of quality enhancement focused material will ensure an interactive and sustainable tool to aid the improvement of engineering education for years to come. Thus, the project paves the way for a dialogue among institutions in order to be proactive and to propose effective and holistic solutions to future risks. The next project activities will explore the full implementation of the process in the European partner institutions and analyse the iterative nature of its development as the results produced from the pilot phase of the project become available.

\section{ACKNOWLEDGMENT}

This work has been funded with support from the European Commission in the context of the 2014-2016 Erasmus+ QAEMP (Key Action2, cooperation, innovation and the exchange of good practices). This paper reflects only the views of the authors. The Commission is not responsible for any use that may be made of the information contained therein. More information on the QAEMP project can be found at www. cross-sparring.eu.

\section{REFERENCES}

[1] (September 2011). Supporting growth and jobs - an agenda for the modernisation of Europe's higher education systems. Available: http://eurlex.europa.eu/legal-content/EN/ALL/?uri=CELEX:52011DC0567.

[2] A. Amaral and M. J. Rosa, "Recent Trends in Quality Assurance," Quality in Higher Education, vol. 16, pp. 59-61, 2010.
[3] M. C. Van der Wende and D. F. Westerheijden, "International aspects of quality assurance with a special focus on European higher education," Quality in Higher Education, vol. 7, pp. 233-245, 2001.

[4] (June 2015). ENAEE - European Network for Accreditation of Engineering Education. Available: http://www.enaee.eu/

[5] (June 2015). ABET. Available: http://www.abet.org/.

[6] (June 2015). Home | Engineers Australia. Available: https://www.engineersaustralia.org.au/.

[7] (June 2015). The Quality Assurance Agency for Higher Education (QAA). Available: http://www.qaa.ac.uk/en.

[8] (June 2015). CTI (Commission des Titres d'Ingénieur). Available: http://www.cti-commission.fr/spip.php?page=sommaire-en.

[9] (June 2015). The Danish Accreditation Institution. Available: http://en.akkr.dk/.

[10] A. Sursock, "Reflection from the higher education institutions' point of view: Accreditation and quality culture," in International Conference on Accreditation and Quality Assurance, 2002, pp. 13-18.

[11] A. Amaral, "Recent trends in quality assurance." in Proceedings of the A3ES and CIPES Conference Recent Trends in Quality Assurance Announcement, Porto, Portugal, 2012, .

[12] G. Neave, "The Politics of Quality: Developments in Higher Education in Western Europe 1992-1994," European Journal of Education, vol. 29, pp. 115134,1994

[13] D. Dill, P. Teixeira, B. Jongbloed and A. Amaral, "Conclusion," in Markets in Higher Education : Rhetoric Or Reality?, P. Teixeira, B. Jongbloed, D. Dill and A. Amaral, Eds. London, United Kingdom: Kluwer Academic Publishers, 2004,

[14] (June 2015). The EFQM Excellence Model | EFQM. Available: http://www.efqm.org/the-efqm-excellence-model.

[15] M. C. Paulk, B. Curtis, M. B. Chrissis and C. V. Weber, "Capability maturity model, version 1.1," Software, IEEE, vol. 10, pp. 18-27, 1993.

[16] A. Mitasiunas and L. Novickis, "Enterprise SPICE based education capability maturity model," in Workshops on Business Informatics Research, 2012, pp. 102-116.

[17] E. B. Boele, H. Burgler and H. Kuiper, "Using EFQM in higher education: Ten years of experience with programme auditing at Hanzehogeschool Groningen," Beiträge Zur Hochschuleforschung, vol. Heft 1, pp. 94-110, 2008.

[18] S. Rouvrais and C. Lassudrie, "Educational program evaluations: Rationalizing assessment models and processes for engineering education quality enhancement," in CDIO 2014: 10th International Conference Conceive Design Implement Operate on Sharing Successful Engineering Education Experiences, 2014,

[19] W. M. Phillips, G. D. Peterson and K. B. Aberle, "Quality assurance for engineering education in a changing world," International Journal of Engineering Education, vol. 16, pp. 97-103, 2000.

[20] (June 2015). A Valued Credential| ABET. Available: http://www.abet.org/accreditation/why-abet-accreditation-matters/a-valuedcredential/\#programs.

[21] O. Filippakou and T. Tapper, "Quality assurance and quality enhancement in higher education: contested territories?" Higher Education Quarterly, vol. 62, pp. 84-100, 2008.

[22] D. Houston, "Rethinking quality and improvement in higher education," Quality Assurance in Education, vol. 16, pp. 61-79, 2008.

[23] E. F. Crawley, M. J., S. Östlund, D. R. Brodeur and K. Edström, Rethinking Engineering Education - the CDIO Approach. Kluwer Academic Publishers Dordrecht ; London, 2014.

[24] (December 2010). The CDIO standards v 2.0. Available: http://www.cdio.org/files/standards/CDIOStds\&Rubricsv2.0_2010Dec8.pdf.

[25] J. Kontio, J. Roslöf, K. Edström, S. Thyberg Naumann, P. Munkebo Hussmann, K. Schrey-Niemenmaa and M. Karhu, "Quality assurance with 
CDIO self-evaluation-first results of A nordic project," in Proceedings of the 7th CDIO Conference, 2011, pp. 20-23.

[26] J. Kontio, K. Heikkinen, F. Georgsson, J. Bennedsen, R. Clark, A. Matthiasdottir, P. Hermon, S. Rouvrais and M. Karhu, "QA and enhancement marketplace for HEIs - an ERASMUS+ project," in Proceedings of the 11th CDIO Conference, June, Chengdu, China, 2015.

[27] R. Clark, J. Bennedsen, S. Rouvrais, J. Kontio, K. Heikkenen, F. Georgsson, A. Matthiasdottir, I. Soemundsdottir, M. Karhu, K. SchreyNiemenmaa and P. Hermon, "Developing a robust self evaluation framework for active learning: The first stage of an ERASMUS+ project (QAEMarketPlace4HEI)," in Proceedings of the 43rd SEFI Annual Conference, June, Orleans, France, 2015.

[28] K. Schrey-Niemenmaa, "Development of a Unit Level Quality System for Engineering Education. Master Thesis, Aalto University, Finland," 2011.
[29] J. Kontio, J. Roslöf, K. Edström, S. Naumann, P. M. Hussmann, K. Schrey-Niemenmaa and M. Karhu, "Improving Quality Assurance with CDIO Self-Evaluation: Experiences From a Nordic Project," International Journal of Quality Assurance in Engineering and Technology Education (IJQAETE), vol. 2, pp. 55-66, 2012.

[30] J. Kontio, P. Granholm, H. Valmu, J. Mäntykoski, K. Kruusamäe, M Aukstuiliene, L. Savulioiene, P. M. Hussmann and K. Edström, "Educational program evaluations: Rationalizing assessment models and processes for engineering education quality enhancement," in Proceedings of the International Conference on Engineering Education 2012, 2012, pp. 816-823.

[31] Frans A. van Vught,Frank Ziegele, Multidimensional Ranking: The Design and Development of U-Multirank. Springer, 2012. 